\title{
Dietary habits and metabolic risk factors for non-communicable diseases in a university undergraduate population
}

\author{
F. A. Olatona ${ }^{{ }^{*}} \mathbb{D}$, O. O. Onabanjo ${ }^{2}$, R. N. Ugbaja ${ }^{3}$, K. E. Nnoaham ${ }^{4}$ and D. A. Adelekan²
}

\begin{abstract}
Background: Unhealthy dietary patterns are associated with metabolic changes and increased risk of noncommunicable diseases (NCDs), but these associations have not been investigated in representative populations of university undergraduates in low-to-middle income countries (LMICs).

Methods: This study was conducted in the three universities in Lagos State, Nigeria to assess the dietary pattern and metabolic risk factors of NCDs among university undergraduate population. Multistage sampling technique was used to select 506 undergraduates from the universities. Pre-tested questionnaire was used to obtain data on sociodemographic characteristics and dietary patterns. Body mass index and metabolic risk factors (abdominal obesity, dyslipidemias, high blood pressure and hyperglycemia) were assessed following standard procedures. SPSS (version 20) was used for data entry and analysis. Association between variables was determined using chi-square and Fisher's exact tests.

Results: The mean age was $20.3 \pm 3.5$ years; $54.7 \%$ of them were female. More than one third (37.6\%) had no consistent source of income or received less than N10, 000 (\$31.7) per month. Less than one third (31.0\%) ate three daily meals, 23. $0 \%$ ate breakfast regularly, and only $2 \%$ consumed the recommended daily amount of fruits and vegetables. Almost half (44.0\%) ate pastry snacks daily. Refined rice was the commonest cereal (28.2\%) consumed while meat was more commonly consumed daily (32.0\%) than milk (14.0\%) and fish (10.0\%). Twenty-nine (29.0\%) and 6.2\% of the population daily consumed carbonated soft drinks and alcohol, respectively. Prevalence of abdominal obesity (based on waist circumference) was $5 \%$ (1.3\% in males and $8.4 \%$ in females), dyslipidemias (57.3\%), pre-hypertension (8.2\%), hypertension (2.8\%), and pre-diabetes (1.0\%). Obesity was positively associated with consumption of alcohol $\left(x^{2}=13.299, p<0.001\right)$.

Conclusion: Unhealthy diets and metabolic risk factors of non-communicable diseases are prevalent in the undergraduate population studied. Well-recognized recommendations regarding adequate consumption of fruits, vegetables, fish, and whole grains should be emphasized in a targeted manner in this population. Carbonated soft drinks and alcohol consumption should be discouraged to stem a rising tide of metabolic risk factors for non-communicable diseases among undergraduate students.
\end{abstract}

Keywords: Dietary pattern, Metabolic risk factors, Non-communicable diseases, University undergraduate students, Nigeria

\footnotetext{
* Correspondence: folaton@gmail.com

'Department of Community Health and Primary Care, College of Medicine,

University of Lagos, Lagos, Lagos State, Nigeria

Full list of author information is available at the end of the article
}

(c) The Author(s). 2018 Open Access This article is distributed under the terms of the Creative Commons Attribution 4.0 International License (http://creativecommons.org/licenses/by/4.0/), which permits unrestricted use, distribution, and reproduction in any medium, provided you give appropriate credit to the original author(s) and the source, provide a link to the Creative Commons license, and indicate if changes were made. The Creative Commons Public Domain Dedication waiver (http://creativecommons.org/publicdomain/zero/1.0/) applies to the data made available in this article, unless otherwise stated. 


\section{Background}

Unhealthy diets are a key modifiable behavioral risk factor for non-communicable diseases (NCDs). They contribute to the occurrence of a cluster of disorders known as the metabolic syndrome-abdominal obesity, hypertension, dyslipidemia, and disturbed metabolism of glucose or insulin-which in turn accounts for a significant share of the global burden of disease [1]. The presence of the metabolic syndrome increases the risk of developing NCDs such as cardiovascular diseases, diabetes, chronic respiratory diseases, and cancer [2, 3].

In recent decades, the global pattern of unhealthy diets driving the occurrence of metabolic disorders and NCDs has become more important in low-to-middle income countries (LMICs) because of the double burden of diseases in such countries. In high-income countries, an epidemiological transition has effectively occurred but in LMICs, infectious and NCDs now jointly constitute major causes of morbidity and mortality [3]. In South Western Nigeria, for example, previous research revealed that only $60 \%$ of university undergraduates consumed the recommended minimum number of servings of grain (cereal) foods while $60 \%, 85 \%$, and $40 \%$ of students did not meet the recommended dietary allowance (RDA) for protein, calcium, and iron respectively. Consumption of meat, milk, and fruits and vegetable was low, and in the same study, body mass index (BMI) classification indicated that $29 \%$ of the students were overweight, $6 \%$ were obese, and $13 \%$ of the male students were underweight [4].

The dietary habits of populations (including young adults) in low-to-middle income countries similarly have rapidly shifted to less-healthy diets (consisting of processed foods, away-from-home food intake, and increased use of edible oils and sugar-sweetened beverages) in line with the global nutrition transition [5]. Young adults are thought to be prone to obesity in the transition from childhood/adolescence to adulthood [5]. The transition to higher education involves a significant life change, including unfavorable changes in health-related behaviors and weight gain for many students [6,7]. Studies among university students in developing countries have previously shown high prevalence of obesity [8]. Moreover, research has shown that university is a critical period for weight gain in young adults; and that during the transition from secondary school to university, failure of students to adapt to a new environment could have negative consequences on their health behaviors and subsequent weight status [5].

Given the above, it is fair to suggest that adequately sampled university undergraduate student populations offer a useful set of lenses through which population health phenomena and trends in the wider population can be viewed, especially in low-to-middle income countries with typically young adult populations. Although dietary patterns and nutritional status of undergraduates in some Nigerian Universities have been studied $[4,9,10]$, the student populations were not sufficiently representative of the Nigerian young adult population neither were the particular influences on university students' eating habits-such as university characteristics, individual and social environmental determinants [11] — consistent with the predominant patterns in the country's most populous and diverse populations. Furthermore, much remains to be known of the relationships between the well-studied dietary patterns and profile of metabolic disorders in these samples of LMIC young adult populations [11]. This study therefore assessed the dietary pattern and metabolic risk factors of NCDs among university undergraduate students in all the three universities in Lagos State.

\section{Methods}

The study was cross-sectional in design. The study population consisted of full time undergraduate students in the three universities in Lagos State: University of Lagos (UNILAG), Lagos State University (LASU) and Caleb University. The minimum sample size calculated using Cochran's formula and prevalence of those who had normal body mass index from a previous study (52\%) [4] as 'p', the estimated prevalence of expected outcome was 384 . The size was however increased to 506 to take care of non-response. A multistage sampling technique was adopted to select the students from the universities. All the three universities were included. Simple random sampling was used to select four faculties from the 12 in UNILAG and LASU and 1 college from Caleb. Using simple random sampling technique (balloting), at least one quarter of the number of departments was selected from each faculty making 11 from UNILAG, 5 from LASU, and 1 from Caleb. Using sampling proportional to size, students were selected across faculties, departments, and levels depending on the total population of students in each faculty, department, and level. Systematic random sampling technique was employed in each class to select respondents. The number required from each class was used to divide the class list to determine the sampling interval. Twenty percent of those who participated in the questionnaire survey were selected using systematic random sampling to determine participants for blood glucose and lipid profiles.

\section{Data collection}

Validated structured interviewer-administered questionnaire was used to obtain data on socio-demographic and economic status, food frequency questionnaire was used to determine food consumption patterns, anthropometric measurements (weight, height, waist circumference, and hip circumference) were made using standard 
procedures and electronic blood pressure monitor (Omron M2 and M7) were used to measure systolic and diastolic blood pressure. The plasma separated from fasting venous blood samples was used to determine blood glucose and lipid profile spectro-photometrically using Cypress diagnostics kits.

\section{Data analysis}

IBM SPSS Statistics (originally named Statistical Package for Social Sciences) was used for data entry, validation, and analysis. Relevant summary statistics was generated for the variables. Dietary habits were analyzed using frequency tables and anthropometric indices, blood pressure, lipid profile, and fasting blood glucose were compared with WHO standards and classified [12]. Chi-square test was used to determine associations between categorical variables. Statistical tests were regarded as statistically significant if $p$ value $<0.05$.

\section{Results}

\section{Socio-demographic and economic status}

Five hundred and ten undergraduates were invited, but only 503 participated in the study giving a response rate of $98.6 \%$. The age of the students ranged from 15 to 41 years, but the modal age group was 19-24 years (57.9\%) while the average age of the sample population in years was $20.3 \pm 3.5$ with $54.7 \%$ being females. Most of their parents had completed secondary school education (75\%) and lived in self-contained housing units within story buildings (41.6\%), but many students (37.6\%) received less than 30 USD per month or had no consistent source of income (the equivalent of 30 USD is less than the minimum wage for those in the lowest socioeconomic class in the country).

\section{Dietary habits and barriers to eating healthy}

Only $31.0 \%$ of the undergraduates ate three meals in a day. Less than one quarter $(23.0 \%)$ consumed breakfast regularly, $29.0 \%$ drank carbonated soft drinks while almost half of them (46.1\%) ate pastry snacks daily. Almost one quarter $(22.7 \%)$ ate fast foods daily indicating at least 7 meals away from home each week (Table 1).

Refined rice and other processed cereals (most likely sugar coated) were the commonest cereals consumed daily (28.2\%); whole grains, roots, and tubers were rarely eaten. Meat was more commonly consumed (32.0\%) than fish (10.0\%); only $30.0 \%$ of the study population ate fish at least 3 times per week. Only $22.0 \%$ of the respondents ate fruits and vegetables while $6.0 \%$ drank alcohol daily. Little time to prepare meals and inadequate funds were cited as the commonest perceived barriers to healthy eating (Figs. 1 and 2).

\section{Metabolic risk factors}

\section{Abdominal obesity}

The prevalence of abdominal (central) obesity was 5.0\% (1.3\% in males and $8.4 \%$ in females) based on waist
Table 1 Distribution of respondents according to their dietary habits $(N=503)$

\begin{tabular}{lll}
\hline Dietary habits & Freq & Percentage \\
\hline No of meals taken daily & 35 & 7.0 \\
One & 287 & 57.1 \\
Two (2) & 156 & 31.0 \\
Three (3) & 25 & 5.0 \\
$\quad$ Four or more & 221 & 44.0 \\
Daily snack (pastry) intake & & \\
Eating in fast food restaurants & 114 & 22.7 \\
$\quad$ Daily & 95 & 18.9 \\
4-6 times/week & 293 & 58.4 \\
$\quad</=3$ times times/week & 144 & 29.0 \\
Daily soft drinks intake & $(N=144)$ & \\
Amount of soft drinks taken daily & 99 & 68.8 \\
35 ml & 45 & 31.3 \\
$\quad$ /> 70 ml & 115 & 22.9 \\
Daily fruits and vegetable intake & $115)$ & \\
Portions of fruits and vegetables taken $(N=115$ & 81.3 \\
Less than five & 105 & 22.5 \\
Five or more portions & 113 & \\
Daily breakfast consumption & & \\
\hline
\end{tabular}

circumference and 20\% (12.3\%) in males and 26.5\% in females) based on the waist-to-hip ratio (WHR). Cut-off points were determined using WHO cut-off values for abdominal obesity [13]. Prevalence of abdominal obesity was significantly higher among females compared to males $(p<0.001)$ for both WC and WHR (Table 2).

\section{Dyslipidemias, high blood pressure, and hyperglycemia}

More than half of the students had lower-than-normal levels of HDL-C (57.3\%) while $23.8 \%$ had levels of LDL-C higher than the upper limit of normal. Only $8.2 \%$ and 3.0\% had pre-hypertensive systolic (i.e., $120-139 \mathrm{mmHg}$ ) and diastolic (80-89 $\mathrm{mmHg}$ ) blood pressure respectively. The prevalence of hypertension $(\geq 140 / 90 \mathrm{mmHg}$ ) was $2.8 \%$. The prevalence of impaired fasting glucose (pre-diabetes) was 1.0\%; nobody had diabetes (Table 3 ).

\section{Factors associated with metabolic risk factors}

Consumption of alcohol was the only factor associated with obesity $(p<0.001)$. Family history of obesity, breakfast consumption, pastry snacks, or soft drink intake were not associated with obesity in this study. Raised LDL-C was statistically significantly associated with lower mother's level of education $(p=0.008)$ and less healthy methods of obtaining water $(p=0.018)$ which are proxy indicators of socio-economic status of parents (Tables 4 and 5). 
Daily Consumption of foods from different food groups

Percentage (\%)

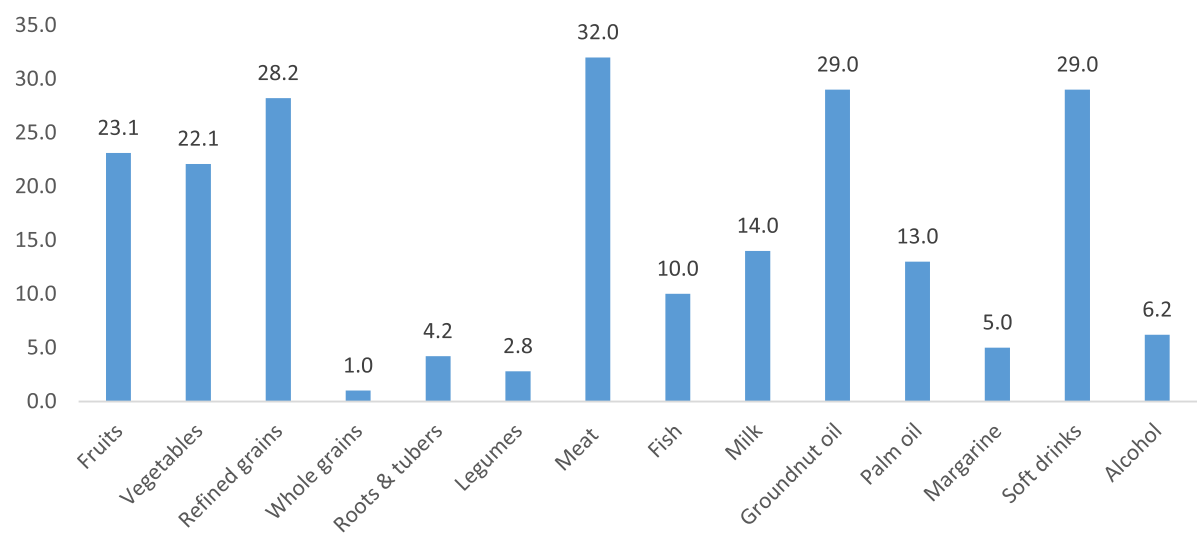

Fig. 1 Daily consumption of different foods

Abdominal obesity was statistically significantly associated with hypertension in this study even though high BMI was not associated with it. $(p<0001)$.

\section{Discussion}

Despite the relatively high level of education or income of parents, many students in the study population lived below the poverty line (\$1.90) per day-receiving less than N10,000 (\$31.76) monthly pocket money or had no consistent source of income-and probably had limited access to healthy diet. Healthier diets cost $\$ 1.48 /$ day and $\$ 1.54 / 2000 \mathrm{kcal}$ more than least healthy diet though the cost of disease is much higher [14].

Only $31 \%$ ate three meals in a day, while others ate less. This finding is consistent with those of other studies among university students in South Western Nigeria, Korea, and Zimbabwe $[4,15,16]$ indicating that most students did not eat the commonly recommended three main meals in a day, and this could lead to malnutrition.
Reasons given for not eating healthful meals include little time to prepare such meals and inadequate funds to purchase food from vendors.

Breakfast consumption was poor among the undergraduates; only $23.0 \%$ of them consumed breakfast daily. This is similar to the proportion of students who consume breakfast in Hail University in Saudi Arabia (28.0\%). Meanwhile, breakfast has been identified as the most important meal in the day necessary for mental work. Whole grains were rarely eaten and refined rice was the commonest cereal consumed daily $(28.2 \%)$, another finding consistent with the report from the United States of America where college students failed to satisfy whole-grain recommendations [17]. This pattern fits into the global trend of increasing numbers of people consuming refined grains rather than whole grains-the so-called nutrition transition.

Less than one quarter of the respondents ate fruits and vegetables daily, and only a few took at least five

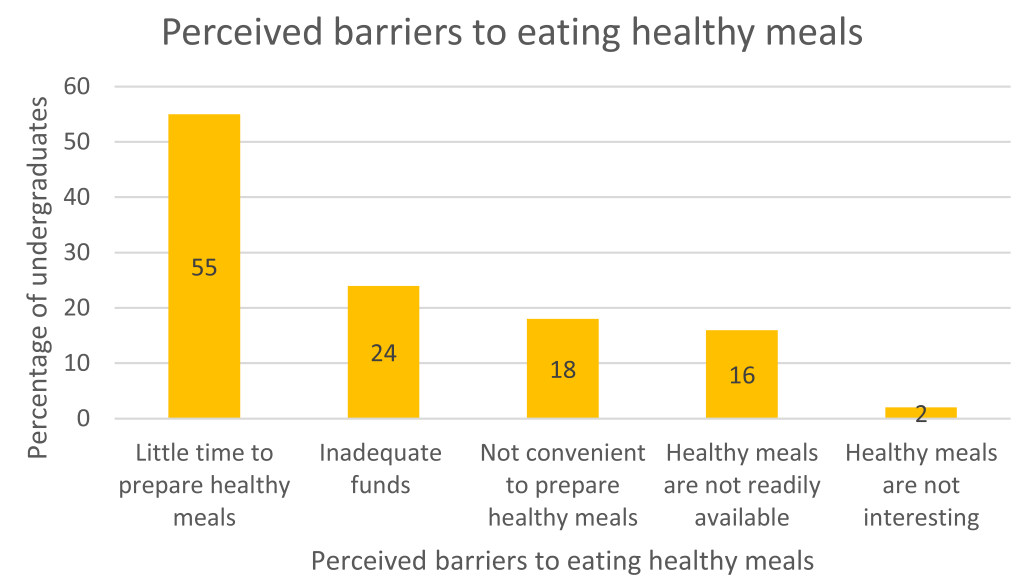

Fig. 2 Respondents' perceived barriers to eating healthy meals 
Table 2 Prevalence of general (BMI) and abdominal (WC and WHR) obesity according to sex

\begin{tabular}{|c|c|c|c|c|c|c|c|c|c|c|c|}
\hline \multirow[t]{2}{*}{ Measure of obesity } & \multicolumn{3}{|c|}{ Male $(N=228)$} & \multicolumn{3}{|c|}{ Female $(N=275)$} & \multicolumn{3}{|l|}{ Total } & \multirow[t]{2}{*}{$x^{2^{*}}$} & \multirow[t]{2}{*}{$\underline{p}$} \\
\hline & $\begin{array}{l}\text { Freq of } \\
\text { normal (\%) }\end{array}$ & $\begin{array}{l}\text { Freq of } \\
\text { overweight (\%) }\end{array}$ & $\begin{array}{l}\text { Freq of } \\
\text { obesity (\%) }\end{array}$ & $\begin{array}{l}\text { Freq of } \\
\text { normal (\%) }\end{array}$ & $\begin{array}{l}\text { Freq of } \\
\text { overweight (\%) }\end{array}$ & $\begin{array}{l}\text { Freq of } \\
\text { obesity (\%) }\end{array}$ & $\begin{array}{l}\text { Freq of } \\
\text { normal (\%) }\end{array}$ & $\begin{array}{l}\text { Freq of } \\
\text { overweight (\%) }\end{array}$ & $\begin{array}{l}\text { Freq of } \\
\text { obesity (\%) }\end{array}$ & & \\
\hline $\begin{array}{l}\text { Body mass } \\
\text { index }\end{array}$ & $168(73.7)$ & $36(16.7)$ & $6(3.0)$ & $202(74.0)$ & $44(16.1)$ & $7(3.3)$ & $370(73.9)$ & $82(16.4)$ & $16(3.2)$ & 0.008 & 0.996 \\
\hline $\begin{array}{l}\text { Waist circumference } \\
\text { (WC) }\end{array}$ & 215(94.3) & $10(4.4)$ & $3(1.3)$ & 188(68.4) & $64(23.3)$ & $23(8.4)$ & 215(94.3) & $74(15.0)$ & $26(5.0)$ & 49.46 & $<0.001$ \\
\hline Waist-to-hip ratio & 200(87.7) & & $28(12.3)$ & 187(68.0) & & $73(26.5)$ & $200(87.7)$ & & $100(20.0)$ & 15.12 & $<0.0$ \\
\hline
\end{tabular}

(WHR)

Body mass index: overweight, $>25-29.99 \mathrm{~kg} / \mathrm{m}^{2}$; obesity, $>30 \mathrm{~kg} / \mathrm{m}^{2}$

Waist circumference (WC: overweight: $>94 \mathrm{~cm}(\mathrm{M}) ;>80 \mathrm{~cm}(\mathrm{~F})$, obesity: $>102 \mathrm{~cm}(\mathrm{M}) ;>88 \mathrm{~cm}(\mathrm{~F})$

Waist-to-hip ratio (WHR): obesity $\geq 0.90 \mathrm{~cm}(\mathrm{M}) ; \geq 0.85 \mathrm{~cm}(\mathrm{~F})$

${ }^{*}$ Chi-square test is for a difference in frequency of obesity between males and females as measured by each method

recommended portions for adults [2]. Majority of the students consumed insufficient quantities of fruits and vegetables. The consumption pattern of fruit and vegetable was poorer than obtained in other universities in South Western Nigeria where $40 \%$ of females and $20 \%$ of males ate adequate amount of fruits and vegetables, and another study in Iran where $51.9 \%$ of the participants ate fruit every day while only $10 \%$ ate it once or twice a week. Another western study revealed that $33.3 \%$ of the students met the healthy eating criteria for vegetables and reported that they had eaten: at least three servings of vegetables on 2.7 days and at least two servings of fruit on 3.4 days $[4,18,19]$. Another study among undergraduates in Enugu however corroborated the findings in this study wherein $28.2 \%$ and $26.7 \%$ consumed fruits and vegetables daily respectively. Kana Sop et al. also found out that undergraduates in Cameroun consumed very little fruits, vegetables, and animal products [19].

Fruits and vegetables are generally more expensive than staple carbohydrate foods like rice and they are not readily available on university campuses probably because they are perishable and not in high demand. Inadequate consumption of this group of foods may be because the students had limited funds to purchase them compared to the cheaper carbohydrate rich foods. About one quarter of the students stated inadequate funds as the major barrier to eating healthy and balanced meals. Limited resources have been highlighted in other studies to greatly compromise dietary patterns [17]. Inadequate fruits and vegetable intake have been singled out as a behavioral risk factor in the development of non-communicable diseases [20].

Table 3 Physiological and biochemical measurements of the respondents

\begin{tabular}{|c|c|c|c|c|c|}
\hline Variable & Upper limit of standard values (mmol/liter) & Freq of normal & Percentage & Frequency of disorder & Percentage \\
\hline Total cholesterol & $<5.2$ & 71 & 67.6 & 34 & 32.4 \\
\hline Triglyceride & $<2$ & 105 & 100 & 0 & 0 \\
\hline HDL-cholesterol & $>1.2$ & 44 & 42.7 & 59 & 57.3 \\
\hline LDL-cholesterol & $<4$ & 80 & 76.2 & 25 & 23.8 \\
\hline Fasting blood glucose & $<=6.1$ & 104 & 99 & 1 & 1 \\
\hline \multicolumn{6}{|l|}{ Blood pressure } \\
\hline & Standard value (mmHg) & Frequency & Percentage & & \\
\hline \multicolumn{6}{|l|}{ Systolic } \\
\hline Optimal BP & $<90$ & 372 & 74.0 & & \\
\hline Normal BP & $90-120$ & 76 & 15.0 & & \\
\hline High normal BP & $120-139$ & 41 & 8.2 & & \\
\hline Hypertensive & $\geq 140$ & 14 & 2.8 & & \\
\hline \multicolumn{6}{|l|}{ Diastolic } \\
\hline Optimal BP & $<60$ & 432 & 85.9 & & \\
\hline Normal BP & $61-80$ & 42 & 8.3 & & \\
\hline High normal BP & $81-89$ & 15 & 3 & & \\
\hline Hypertensive & $\geq 90$ & 14 & 2.8 & & \\
\hline
\end{tabular}

$H D L$ high-density lipoprotein, $L D L$ low-density lipoprotein, $B P$ blood pressure 
Table 4 Socioeconomic and dietary factors associated with general and abdominal obesity

\begin{tabular}{|c|c|c|c|c|c|c|c|c|c|c|c|c|}
\hline \multirow[t]{2}{*}{ Factors } & \multicolumn{4}{|c|}{ General obesity (based on BMI) } & \multicolumn{4}{|c|}{ Abdominal obesity (based on WC) } & \multicolumn{4}{|c|}{ Abdominal obesity (based on WHR) } \\
\hline & $\begin{array}{l}\text { Normal BMl } \\
n(\%)\end{array}$ & $\begin{array}{l}\text { Overweight/ } \\
\text { obesity } n(\%)\end{array}$ & $x^{2}$ & $\overline{p \text { value }}$ & $\begin{array}{l}\text { Normal WC } \\
n(\%)\end{array}$ & $\begin{array}{l}\text { Overweight/ } \\
\text { obesity } n(\%)\end{array}$ & $x^{2}$ & $p$ value & $\begin{array}{l}\text { Normal WHR } \\
n(\%)\end{array}$ & $\begin{array}{l}\text { Overweight/ } \\
\text { obesity } n(\%)\end{array}$ & $x^{2}$ & $p$ value \\
\hline \multicolumn{13}{|l|}{ Income } \\
\hline Not consistent & $87(85)$ & $15(15)$ & & & $87(84.5)$ & $16(15.5)$ & & & $87(84.5)$ & $16(15.5)$ & & \\
\hline $\begin{array}{l}\text { N1000-N5000 } \\
(\$ 3-15)\end{array}$ & $41(83.7)$ & $5(10.2)$ & & & $42(85.7)$ & $7(14.3)$ & & & $34(69.4)$ & $15(30.6)$ & & \\
\hline $\begin{array}{l}\text { N5001-N10000 } \\
(\$ 15-31)\end{array}$ & $61(70.9)$ & $17(19.8)$ & 2.157 & 0.11 & $71(82.6)$ & $15(17.5)$ & 8.996 & 0.53 & $72(83.7)$ & $14(16.3)$ & 7.975 & 0.16 \\
\hline $\begin{array}{l}\text { N10001-N20000 } \\
(32-61)\end{array}$ & $128(76.6)$ & $32(19.2)$ & & & $131(78)$ & $37(22.0)$ & & & $136(81.0)$ & $32(19.0)$ & & \\
\hline $\begin{array}{l}\text { Above N20000 } \\
(>\$ 61)\end{array}$ & $63(64.9)$ & $29(29.9)$ & & & $72(74.2)$ & $25(25.8)$ & & & $74(76.3)$ & $23(23.7)$ & & \\
\hline \multicolumn{13}{|c|}{ Family history of obesity } \\
\hline Yes & $0(0)$ & $7(35.0)$ & & & $13(65.0)$ & $7(35.0)$ & & & $14(70.0)$ & $6(30.0)$ & & \\
\hline No & $33(6.9)$ & $91(18.9)$ & 4.132 & 0.127 & $390(80.7)$ & $93(19.3)$ & 3.904 & 0.15 & $389(80.5)$ & $94(19.5)$ & 1.339 & 0.25 \\
\hline \multicolumn{13}{|l|}{ Pastry snacks intake } \\
\hline Yes & $17(7.4)$ & $49(21.2)$ & & & $187(80.6)$ & $45(19.4)$ & & & $189(81.5)$ & $43(18.5)$ & & \\
\hline No & $16(5.9)$ & $49(18.1)$ & 1.327 & 0.515 & $216(79.7)$ & $55(20.3)$ & 1.105 & 0.58 & $214(79.0)$ & $57(21.0)$ & 0.49 & 0.48 \\
\hline \multicolumn{13}{|l|}{ Soft drinks } \\
\hline Yes & $5(3.4)$ & $24(16.6)$ & & & $50(59.5)$ & $34(40.5)$ & & & $53(67.1)$ & $47(26.0)$ & & \\
\hline No & $28(7.9)$ & $74(20.8)$ & 5.041 & 0.08 & $138(72.3)$ & $53(27.7)$ & 5.497 & 0.06 & $134(74.0)$ & $26(32.9)$ & 1.313 & 0.25 \\
\hline \multicolumn{13}{|c|}{ Breakfast consumption } \\
\hline Everyday & $7(6.2)$ & $25(22.1)$ & & & $85(75.2)$ & $28(24.8)$ & & & 90 (79.6) & $23(20.4)$ & & \\
\hline Occasionally & $17(6.6)$ & $47(18.1)$ & 0.885 & 0.927 & $218(83.8)$ & $42(16.2)$ & 5.701 & 0.22 & $211(81.2)$ & 49 (18.8) & 0.415 & 0.81 \\
\hline Always skipped & $9(7.0)$ & $26(20.2)$ & & & $100(76.9)$ & $30(23.1)$ & & & $102(78.5)$ & $28(21.5)$ & & \\
\hline \multicolumn{13}{|l|}{ Alcohol consumption } \\
\hline Yes & $4(4.9)$ & $28(34.1)$ & & & $30(62.5)$ & $18(37.5)$ & & & $31(72.1)$ & $12(27.9)$ & & \\
\hline No & $29(6.9)$ & $70(16.7)$ & 13.299 & 0.001 & $158(69.6)$ & $69(30.4)$ & 1.557 & 0.46 & $156(71.9)$ & $61(28.1)$ & 0.001 & 0.98 \\
\hline
\end{tabular}

Almost $30 \%$ of the respondents (29.0\%) drank carbonated soft drinks daily while $25.0 \%$ drank it 4-6 times in a week. The prevalence of daily consumption of carbonated soft drink is similar to what was obtained in University of Ibadan, Nigeria, (27.1\%) although lower than what was obtained in Cincinnati (51.2\%) and North America (65.0\%) [21, 22]. The major challenge with consumption of carbonated soft drink is the excessive consumption of refined sugar which can lead to obesity and hence other risk factors of NCDs. Research has shown that increase in prices of such drinks leads to a lower demand for them, increased demand for alternative drinks like non-sugary fruit juice and hence decrease in BMI and the prevalence of overweight and obesity [23]. Taxes and subsidies are likely to be an effective intervention to reduce consumption of carbonated soft drinks and other unhealthy foods associated with obesity and chronic disease, with evidence showing a consistent effect on consumption across a range of tax rates [24].

Almost half of the students ate pastry snack and ate it more than three times daily. This study is in congruence with others which showed that college students consume excessive calories from high-fat snack foods and fast food and eat little nutrient-dense foods (fruits, vegetables, and low-fat dairy) $[25,26]$. Almost one quarter of the respondents ate in fast food restaurants daily indicating that at least seven [7] meals were taken away from home each week. This is similar to another study where most of the students ate average of 6.1 meals in restaurants every week [21]. Frequent visits to fast food restaurants are most likely because of their proximity to the students. Fast food restaurants have multiplied rapidly over the years due to nutrition transition and globalization; meanwhile, research has shown that proximity to fast food restaurant encourages its patronage [27, 28]. The challenge with pastry snacks and fast foods are high level of fat and calorie which are implicated as risk factors for NCDs.

Meat was more commonly consumed than fish. Only $30.0 \%$ of the respondents ate fish more than three times a week. Although this low proportion is higher than the proportion obtained from students in Azad University ( $47.2 \%$ ate fish once or twice a month), it is too low in 
Table 5 Association between selected socio-economic characteristics and raised LDL-cholesterol

\begin{tabular}{|c|c|c|c|c|c|}
\hline & Normal LDL-C & Raised & Total & $x^{2}$ & $p$ value \\
\hline & $n(\%)$ & LDL-C n (\%) & $n(\%)$ & & \\
\hline \multicolumn{6}{|l|}{ Sex } \\
\hline Male & $13(27.1)$ & $35(72.9)$ & $48(100)$ & & \\
\hline Female & $12(21.1)$ & $45(78.9)$ & $57(100)$ & 0.521 & 0.31 \\
\hline \multicolumn{6}{|l|}{ Mother's level of education } \\
\hline No education & $1(100)$ & $0(0)$ & $1(100)$ & & \\
\hline Informal education & $6(80.0)$ & $1(20.0)$ & $7(100)$ & & \\
\hline Primary education & $3(33.0)$ & $6(67.0)$ & $9(100)$ & & \\
\hline Secondary education & $14(78.0)$ & $4(22.0)$ & $18(100)$ & 21.74 & $0.008^{*}$ \\
\hline Some tertiary & $56(80.0)$ & $14(20.0)$ & $70(100)$ & & \\
\hline \multicolumn{6}{|c|}{ Parents' methods of obtaining water } \\
\hline Pipe-borne & $77(79.4)$ & $20(20.6)$ & & & \\
\hline Well & $3(42.9)$ & $4(57.1)$ & $7(100)$ & 8.03 & $0.018^{*}$ \\
\hline Stream & $0(0.0)$ & $1(100)$ & $1(100)$ & & \\
\hline \multicolumn{6}{|l|}{ Pocket money/income } \\
\hline Not consistent & $13(81.3)$ & $3(18.8)$ & $16(100)$ & & \\
\hline N1000-N5000 (\$3-15) & $7(58.3)$ & $5(41.7)$ & $12(100)$ & & \\
\hline N5001-N10000 (\$15-31) & 17 (77.3) & $5(22.7)$ & $22(100)$ & 6.74 & 0.244 \\
\hline N10001-N20000 (32-61) & $32(76.2)$ & $10(23.8)$ & $42(100)$ & & \\
\hline Above N20000 (> \$61) & $11(84.6)$ & $2(15.4)$ & $13(100)$ & & \\
\hline
\end{tabular}

*Fishers' exact test

view of WHO recommendation that people should eat fish at least three times weekly especially because of the healthy polyunsaturated fatty acids. There is an association between adequate fish intake and reduced risk of early and late age-related macular degeneration (AMD) [29].

In this study, the prevalence of abdominal obesity (by waist circumference or waist-to-hip ratio) was higher than general obesity. Meanwhile, abdominal obesity has been shown to be better predictor of NCDs than general obesity [30].

Family history of obesity or breakfast consumption were not associated with obesity in this study compared to other studies where family history of obesity and skipping of breakfast were predictive of overweight and obesity. Other studies consistently show that breakfast skippers are more likely to be obese than people who eat breakfast [31, 32]. However, alcohol consumption was positively associated with general obesity (based on body mass index). Alcohol consumption has been shown to be a risk factor for obesity and the association is a dose-response relationship [33, 34].

Low HDL-c was the most common dyslipidemia in the study population (57.3\%) and was more frequent compared to another report obtained in South Western Nigeria $(43.1 \%)$ and USA $(20.1 \%)[35,36]$. The prevalence of high LDL-C (23.8\%) was however consistent with reports from South Eastern Nigeria. (21.7\%) [37].
Low HDL-C actually constitutes a higher risk factor for NCDs compared to high LDL-C [38]. The high prevalence of low HDL-C is most likely because most of the students consumed processed foods especially biscuits, snacks pastries, and margarine which have a lot of fat especially trans-fat more than whole and natural foods such as fruits, vegetables, and fermented foods which have pre-biotics and pro-biotics.

Moreover, many of them used vegetable or groundnut oil often which is most likely the commonly available cheap oil that are heat pressed and contains trans-fat. These snacks foods, margarine, and heat-pressed oil contain trans-fat which is implicated in reducing the healthful HDL-C and increasing the un-healthful LDL-C. Trans-fat also causes many other health problems such as obesity, metabolic disorders, and impairment of the metabolism of long-chain polyunsaturated fatty acids (LC-PUFAs). Excessive trans-fatty acid intake in pregnancy has been shown to reduce LCPUFAs levels in infants at birth, meanwhile LCPUFAs are responsible for the positive association between breastfeeding and intelligence $[39,40]$ On the other hand, prebiotics and probiotics which can be obtained from fruits, vegetables, and fermented foods have been known to lower cholesterol [41].

Raised LDL-C was associated with lower mothers' level of education and worse methods of obtaining water which are proximate of the socio-economic status of the 
students. This means that the poorer students were more likely to have dyslipidemia. This is in consonant with recent finding which show that the earlier labeling of chronic diseases as "diseases of affluence" is increasingly a misnomer and there is a global shift of the burden of NCDs toward the poor [42].

The prevalence of hypertension in this study $(2.8 \%)$ was similar to that of students in Central University in the West Bank (2.2\%) but lower than obtained from another study in Makerere University where $54.0 \%$ and $11.0 \%$ had systolic pre-hypertension and hypertension and $43.0 \%$ and $18.0 \%$ were hypertensive $[34,43]$. The prevalence of hypertension among these undergraduates was also lower than that obtained from other Nigerian studies $\{(20.8 \%)$ and $(16.3 \%)\}$ most likely because blood pressure increases with age and the other studies were conducted among adults $[38,40]$.

Abdominal obesity was statistically significantly associated with hypertension in this study even though high BMI was not associated with it. Abdominal obesity has been shown to be more highly correlated with the metabolic risk factors compared with elevated BMI. If obesity is defined in terms of waist-to-hip ratio (WHR) instead of BMI, the percentage of populations categorized as being at risk of heart attack will increase by threefold worldwide [44].

The prevalence of impaired fasting glucose (pre-diabetes) was $1 \%$, but nobody had diabetes. This is very rare compared to other studies. For instance, a study among students of the University of Kansas showed that 9.0\% had impaired fasting glucose while another study among adults in South Western Nigeria reported 2.5\% [45, 46].

\section{Limitations of the study}

Only chi-square test was employed in statistical analysis and this might not have been sensitive enough since many confounders could likely change the results of the association.

\section{Conclusions}

Consumption of processed foods was high while that of fruits, vegetables, whole grains, and legumes was very low. This unhealthy dietary pattern along with alcohol consumption was associated with abdominal obesity. High prevalence of dyslipidemia was associated with low socio-economic status of parents. Undergraduate students are at risk of obesity and other metabolic risk factors of NCDs. Undergraduates in Lagos need to desist from alcohol consumption and consume more energy from whole foods that are rich in fiber for management of obesity. This result is useful for policy-makers in identifying specific areas where intervention is needed to improve diet and prevent metabolic risk factors of NCDs among university undergraduates, thus reducing morbidity and mortality in later adulthood and beyond.

\section{Abbreviations}

HDL: High-density lipoprotein; LDL: Low-density lipoprotein; LMIC: Low-tomiddle income countries; NCD: Non-communicable diseases

\section{Acknowledgements}

The authors wish to acknowledge the deans of students' affairs of the three universities for granting permission to collect data.

\section{Funding}

The research was funded by the authors.

Availability of data and materials

The datasets used and analyzed during the current study are available from the corresponding author on reasonable request.

\section{Authors' contributions}

FO, OO, DA, RU, and KN conceptualized and designed the study. FO acquired and interpreted the data. FO, OO, and KN drafted the manuscript and critically revised it for important intellectual content. KN was a major contributor in writing the manuscript. All authors read and approved the final manuscript.

\section{Ethics approval and consent to participate}

The study was conducted according to the guidelines laid down in the Declaration of Helsinki. Ethical approval was obtained from the Health Research and Ethics Committee of the Lagos University Teaching Hospital (Ref No: ADM/ DCST/HREC/APP/179 and Lagos State University Teaching Hospital (Ref No: LREC/10/06/630). Informed written consent was obtained from all students as well as parental consent from those who were younger than 18 years of age before conducting the study, and confidentiality was maintained.

Consent for publication

Not applicable

Competing interests

The authors declare that they have no competing interests.

\section{Publisher's Note}

Springer Nature remains neutral with regard to jurisdictional claims in published maps and institutional affiliations.

\section{Author details}

${ }^{1}$ Department of Community Health and Primary Care, College of Medicine, University of Lagos, Lagos, Lagos State, Nigeria. ${ }^{2}$ Department of Nutrition and Dietetics, College of Food Science and Human Ecology, Federal University of Agriculture, Abeokuta, Nigeria. ${ }^{3}$ Department of Biochemistry, Federal University of Agriculture, Abeokuta, Nigeria. ${ }^{4}$ Faculty of Health and Human Sciences, Plymouth University, Plymouth, England.

Received: 10 April 2018 Accepted: 4 August 2018

Published online: 16 August 2018

\section{References}

1. Alberti K, George MM, Zimmet P, Shaw J. The metabolic syndrome? A new worldwide definition. Lancet. 2005;366:1059-62.

2. Grundy SM, Cleeman JI, Daniels SR, Donato KA, Eckel RH, Franklin BA. Diagnosis and management of the metabolic syndrome: an American Heart Association/national heart, lung, and blood institute scientific statement. Circulation. 2005;112(17):2735-52. https://doi.org/10.1161/Circulation AHA. 105.169404

3. Agyei-Mensah S, de-Graft Aikins A. Epidemiological transition and the double burden of disease in Accra, Ghana. J Urban Health. 2010;87(5):87997. https://doi.org/10.1007/s11524-010-9492-y.

4. Otemuyiwa IO, Adewusi SR. Food choice and meal consumption pattern among undergraduate students in two universities in southwestern Nigeria. Nutr Health. 2012;21(4):233-45. https://doi.org/10.1177/0260106013510994.

5. Popkin BM, Adair LS, Ng SW. NOW AND THEN: The global nutrition transition: the pandemic of obesity in developing countries. Nutr Rev. 2012; 70(1):3-21. https://doi.org/10.1111/j.1753-4887.2011.00456.

6. Crombie AP, llich JZ, Dutton GR, Panton LB, Abood DA. The freshman weight gain phenomenon revisited. Nutr Rev. 2009;67(2):83-94. 
7. Deforche B, Dyck DV, Deliens T, Bourdeaudhuij ID. Changes in weight, physical activity, sedentary behaviour and dietary intake during the transition to higher education: a prospective study. Int I Behav Nutr Phys Act. 2015;12:16. https://doi.org/10.1186/s12966-015-0173-9.

8. Kassas GE. Obesity risk factors among Beirut Arab University students in TripoliLebanon. J Nutr Food Sci. 2015:5:421. https://doi.org/10.4172/2155-9600.1000421.

9. Onyechi UA, Okolo AC. Prevalence of obesity among undergraduate students, living in halls of residence, University of Nigeria, Nsukka Campus, Enugu State. Animal Res Int. 2008;5(3):928-931 928.

10. Adu OB, Falade AM, Nwalutu EJ, Elemo BO, Magbagbeola OA. Nutritional status of undergraduates in a Nigerian university in south-west Nigeria. Int $J$ Med Med Sci. 2009;8:318-24.

11. Deliens T, Clarys P, De Bourdeaudhuij I, Deforche B. Determinants of eating behaviour in university students: a qualitative study using focus group discussions. BMC Public Health. 2014;14(1):53.

12. Beers MH and Andrew J.F. The Merck Manual of Medical Information. 2nd ed. Whitehouse Station: Merck Research Laboratories,2003;1900.

13. World Health Organization. Obesity: preventing and managing the global epidemic: report of a WHO Consultation on Obesity, Geneva; 1997.

14. Rao M, Afshin A, Singh G, et al. Do healthier foods and diet patterns cost more than less healthy options? A systematic review and meta-analysis. BMJ Open. 2013;3:e004277. https://doi.org/10.1136/bmjopen-2013-004277.

15. Sakamaki R, Amamoto R, Mochida Y, Shinfuku N, Toyama K. A comparative study of food habits and body shape perception of University students in Japan and Korea. Nutr J Korea. 2005;4:31. https://doi.org/10.1186/1475-2891-4-31.

16. Manwa L. University students' dietary patterns: a case of a University in Zimbabwe. J Emerg Trends Educ Res Policy Stud. 2013;4(1):191.

17. Rose N, Hosig K, Davy B, Serrano E, Davis L. Whole-grain intake is associated with body mass index in college students. J Nutr Educ Behav. 2007;39:90-4.

18. King KA, Mohl K, Bernard AL, Vidourek RA. Does involvement in healthy eating among university students differ based on exercise status and reasons for exercise. Californian J Health Promot. 2007:5(3):106-19.

19. Kana Sop MM, Gouado I, Tetanye E, Amvam Zollo PH. Nutritional status, food habits and energy profile of young adult Cameroonian university students. Afr J Food Sci. 2010;4(12):748-53.

20. World Health Organization. Report of the formal meeting of member states to conclude the work on the comprehensive global monitoring framework, including indicators, and a set of voluntary global targets for the prevention and control of non-communicable diseases. Geneva; 2012; Available from:http:/apps. who.int/gb/ncds/pdf/A NCD 2-en.pdf [Accessed 16 Mar 2016].

21. Fadupin GT, Ogunkunle MO, Gabriel OO. Knowledge, attitude and consumption pattern of alcoholic and sugar sweetened beverages among undergraduates in a Nigerian institution. Afr J Biomed Res. 2014;17(2):75-82.

22. West DS, Bursac Z, Quimby D, Prewitt TE, Spatz T, Nash C, et al. Selfreported sugar-sweetened beverage intake among college students. Obesity (Silver Spring). 2006;14(10):1825-31.

23. Cabrera EMA, Veerman JL, Tollman SM, Bertram MY, Hofman KJ. Evidence that a tax on sugar sweetened beverages reduces the obesity rate: a meta-analysis. BMC Public Health. 2013;13(1):1072. https:/doi.org/10.1186/1471-2458-13-1072

24. Thow AM, Downs S, Jan S. A systematic review of the effectiveness of food taxes and subsidies to improve diets: understanding the recent evidence. Nutr Rev. 2014;72(9):551-65.

25. Nishida C, Uauy R, Kumanyika S, Shetty P. The joint WHO/FAO expert consultation on diet, nutrition and the prevention of chronic diseases: process, product and policy implications. Public Health Nutr. 2004;7(1A):245-50.

26. Irazusta A, Hoyos I, Irazusta J, Ruiz F, Diaz E, Gil J. Increased cardiovascular risk associated with poor nutritional habits in first-year university students. Nutr Res. 2007;27:387-94

27. Olayiwola K, Soyibo A, Atinmo T. Impact of globalization on food consumption, health and nutrition in Nigeria. paper prepared for FAO technical workshop on "globalization of food systems: impact on food security and nutrition" in Rome, Italy. 2003; (online). http://www.fao.org/ tempref/docrep/fao/007/y5736e/y5736e01.pdf.

28. Athens JK, Duncan DT, Elbel B. Proximity to fast-food outlets and supermarkets as predictors of fast-food dining frequency. J Acad Nutr Diet. 2016;S2212-2672(15):01842-0. https://doi.org/10.1016/j.jand.2015.12.022.

29. Chong EWT, Kreis AJ, Wong TY, Simpson JA, Guymer RH. Dietary $\omega-3$ fatty acid and fish intake in the primary prevention of age-related macular degeneration. Arch Ophthalmol. 2008;126(6):826-33. https://doi.org/10.1001/archopht.126.6.826.

30. Vazquez G, Duva S, David R, Jacobs J, Silventoinen K. Comparison of body mass index, waist circumference, and waist/hip ratio in predicting incident diabetes: a meta-analysis. Epidemiol Rev. 2007;29(1):115-28. https://doi.org/ 10.1093/epirev/mxm008.

31. Yasin IT, Nagham AY, Wiam TK, Lama O, Abu R, Ahmad BR, Mohammad HS. Prevalence and risk factors of obesity and hypertension among students at a central university in The West Bank. Libyan J Med. 2012;7 https://doi.org/ 10.3402/ljm.v7i0.19222.

32. Cho S, Dietrich M, Brown CJ, Clark CA, Block G. The effect of breakfast type on total daily energy intake and body mass index: Results from the third National Health and Nutrition Examination Survey (NHANES III). J Am Coll Nutr. 22(4):296-302.

33. Raimi $\mathrm{TH}$, Odusan $\mathrm{O}$, Fasanmade $\mathrm{O}$. High prevalence of central obesity in rural South-Western Nigeria: need for targeted prevention. J Diabetes Endocrinol. 2015;6(3):12-8.

34. Croezen S, Visscher TLS, Ter-Bogt NCW, Veling ML, Haveman-Nies A. Skipping breakfast, alcohol consumption and physical inactivity as risk factors for overweight and obesity in adolescents: results of the E-Movo project. Eur J Clin Nutr. 2009:63:405-12. https:/doi.org/10.1038/sj.ejcn.1602950.

35. Oladapo OO, Salako L, Sodiq O, Shoyinka K, Adedapo K, Falase AO. A prevalence of cardiometabolic risk factors among a rural Yoruba southwestern Nigerian population: a population-based survey: cardiovascular topics. Cardiovasc J Afr. 2010;21(1):26-31.

36. Fernandes J, Lofgren IE. Prevalence of metabolic syndrome and individual criteria in college students. J Am Coll Heal. 2011;59:313-21.

37. Oguejiofor OC, Onwukwe CH, Odenigbo CU. Dyslipidaemia in Nigeria: prevalence and pattern. Ann Afr Med. 2012;11(4):197-202.

38. Barter P, Gotto AM, LaRosa JC, Maroni J, Szarek M, Grundy SM. HDL cholesterol, very low levels of LDL cholesterol, and cardiovascular events. N Engl J Med. 2007;357(13):1301-10.

39. Mojska H. Influence of trans-fatty acids on infant and fetus development. Acta Microbiol Pol. 2003; 52: Suppl:67-74. PMID 15058815.

40. Food and Nutrition Board, Institute of Medicine of The National Academies. Dietary Reference Intakes For Energy, Carbohydrate, Fiber, Fat, Fatty Acids, Cholesterol, Protein, And Amino Acids (Macronutrients). National Academies Press. 2005; p. 423-504. (Online) https://www.nap.edu/catalog/10490/ dietary-reference-intakes-for-energy-carbohydrate-fiber-fat-fatty-acidscholesterol-protein-and-amino-acids.

41. Risérus U. Trans fatty acids, insulin sensitivity and type 2 diabetes. Scand J Food Nutr. 2006;50(4):161-5.

42. Yoo JY, Kim SS. Probiotics and prebiotics: present status and future perspectives on metabolic disorders. Nutrients. 2016;8(3):E173. https://doi. org/10.3390/nu8030173

43. Popkin BM. Global nutrition dynamics: the world is shifting rapidly toward a diet linked with noncommunicable diseases. Am J Clin Nutr. 2006;84(2):289-98.

44. Bimenya GS, Byarugaba W, Kalungi S, Mayito J, Mugabe K, Makabayi R, Ayebare $\mathrm{E}$, Wanzira $\mathrm{H}$, Muhame M. Blood pressure profiles among Makerere University undergraduate students. Afr Health Sci. 2005;5(2):99-106.

45. Yusuf S, Hawken S, Ounpuu S, Bautista L, Franzosi MG, Commerford P, et al. Obesity and the risk of myocardial infarction in 27,000 participants from 52 countries: A case-control study. Lancet. 2005;366(9497):1640-9. https://doi. org/10.1016/S0140-6736(05)67663-5. PMID 16271645.

46. Huang TT, Shime A, Lee RE, Delancey W, Strother ML. Metabolic syndrome and related disorders. 2007;5(4):365-72. https://doi.org/10.1089/met.2007.0021.

Ready to submit your research? Choose BMC and benefit from:

- fast, convenient online submission

- thorough peer review by experienced researchers in your field

- rapid publication on acceptance

- support for research data, including large and complex data types

- gold Open Access which fosters wider collaboration and increased citations

- maximum visibility for your research: over $100 \mathrm{M}$ website views per year

At $\mathrm{BMC}$, research is always in progress.

Learn more biomedcentral.com/submissions 